\title{
ISOLATION, PURIFICATION, AND CHARACTERIZATION OF PORCINE SKIN COLLAGEN: ANALYSIS OF THE GLYCINE, PROLINE, AND HYDROXYPROLINE COMPONENTS USING HIGH-PERFORMANCE LIQUID CHROMATOGRAPHY
}

\author{
AYU ADITYA ANDAYANI, HARMITA HARMITA*, BAITHA PALANGGATAN MAGGADANI
}

Department of Pharmacy, Faculty of Pharmacy, University of Indonesia, Depok, 16424, Indonesia. Email: igakadeharmita@gmail.com Received: 21 May 2018, Revised and Accepted: 07 October 2018

ABSTRACT

Objective: The aim of this study is to produce collagen through the extraction and isolation of porcine skin.

Methods: Collagen from porcine skin (Sus scrofa domesticus) was isolated, purified, and characterized. Major amino acid content of collagen (glycine, proline, and hydroxyproline) was determined. Samples were extracted with $0.5 \mathrm{~N}$ acetic acid and precipitated with $0.9 \mathrm{M} \mathrm{NaCl}$. Characterization tests included those to determine the organoleptic content, $\mathrm{pH}$, Fourier-transform infrared analysis, moisture content, ash content, viscosity, and Masson's trichrome staining on collagen tissue. The collagen was further analyzed using high-performance liquid chromatography using $\mathrm{C}-18^{\circledR}$ column and a fluorescence detector at $265 \mathrm{~nm}$ and $320 \mathrm{~nm}$, acetic buffer (pH 4.2)-acetonitrile (55:45) as mobile phase, and optimum flow rate of 0.8 mL/min.

Results: Our findings indicated that the best method for isolating collagen was with $0.1 \mathrm{M} \mathrm{NaOH}$ expressed by average contents of glycine, proline, and hydroxyproline in collagen which were $33.663 \pm 0.215 \%, 12.333 \pm 0.128 \%$, and $11.303 \pm 0.354 \%$, respectively.

Conclusion: Porcine collagen has been successfully obtained with this method.

Keywords: Amino acid, Derivatization, Fluorescence, Glycine, High-performance liquid chromatography, Hydroxyproline, Porcine skin collagen, Praline.

(C) 2018 The Authors. Published by Innovare Academic Sciences Pvt Ltd. This is an open access article under the CC BY license (http://creativecommons. org/licenses/by/4. 0/) DOI: http://dx.doi.org/10.22159/ijap.2018.v10s1.65

\section{INTRODUCTION}

For thousands of years, before oil-based synthetic polymers were discovered, collagen was the dominant organic material used to fabricate shoes, clothes, glue, tape, filaments, surgical sutures, and other necessary items. Recently, the demand for collagen and gelatin - the denatured form of collagen - has increased. Collagen is now considered a beneficial biomaterial because it plays a major role in industrial applications, such as in food, clothing, cosmetics, pharmacy, health, and biomedical industry [1-4,8].

Collagen is the most abundant protein in animals and humans, which exists as $30 \%$ of the total protein in tissues and organs. The high demand for collagen in the food industry is fueled by its high protein concentration and functional characteristics, including its high water absorption capacity, gel and emulsion-forming ability, and stabilization ability. In pharmaceutical and biomedical industries, collagen performs several roles in medicine, protein, and gas transport and also acts as a substitute for human skin, blood vessels, and ligaments [2,3]. Raw material used in collagen production can be obtained from several animal resources such as bones, skin, tendons, and the connective tissues of mammals, fish, and birds. However, cows and pigs are the most used sources of collagen because of their economic value, easy availability, and high quantities [3]. Since 2010, interest and demand for porcine collagen have increased in the cosmetic and beauty industries because of the benefits of collagen-based face creams and sleeping packs for hydrating skin, maintaining skin moisture, and fading the fine lines caused by aging and drying [3].

Therefore, in this study, we aimed to produce porcine collagen through the extraction and isolation of pig skin. For the isolation and purification of collagen, we used a method reported by Lestari in 2007 [9], with modification. Briefly, the pre-treatment phase of materials was performed by immersing the samples in $\mathrm{NaOH}(0.1 \mathrm{~N})$, followed by extraction with acetic acid $(0.5 \mathrm{M})$ and precipitation with $\mathrm{NaCl}(0.9 \mathrm{~N})$. The collagen was then centrifuged, and the purification phase was performed through dialysis and freeze-drying to obtain collagen in the solid form. The isolated collagen was characterized through an organoleptic test and evaluations of water and ash content, $\mathrm{pH}$, viscosity, Fourier-transform infrared (FTIR) analysis, and Casson's trichrome staining test.

Theprimaryaminoacids-glycine,proline, and hydroxyproline-contained in porcine collagen were then analyzed. Proline and hydroxyproline contained in collagen are secondary amino acids that lack a chromophore group; therefore, they need to be derivatized with a fluorogenic reactant to form fluorescent elements under ultraviolet rays (UV-Vis). In this study, 9-fluorenylmethyloxycarbonyl chloride (FMOC-Cl) reactant was chosen because of its ability to derivatize primary and secondary amino acids. Further studies were then performed using high-performance liquid chromatography (HPLC), which is more effective and selective in amino acid purification and quantification, complemented with a fluorescence detector.

\section{MATERIALS AND METHODS}

\section{Tools}

The HPLC LC 20AT system (Shimadzu, Japan) comprising a pump, YMCTriart $^{\circledR}$ C18 column, fluorescence detector RF 20A (Shimadzu, Japan), manual injector, and data processor (LC-Solution) was used. HPLC syringes (SGE, Australia), a UV-Vis spectrophotometer (Shimadzu, UV-1601), and an FTIR (Shimadzu 8400S) in conjunction with a DRS8000 was also used. Other equipment commonly used in quantitative analysis included an ultrasonicator (LC $20 \mathrm{H}$ ), oven (Heraeus), furnace (Cole-Parmer, Chemoscience), centrifuge (NF 400R), pH meter (Eutech Instruments pH 510), freeze-dryer (Eyela FDU 1200), vortex (WiseMix VM-10), micropipette (Propete), a Viscometer Ostwald (Schott Gerate), Millipore $45-\mu \mathrm{m}$ filter paper (Whatman), analytic scale, ultrasonicator 
(LC $20 \mathrm{H}$ ), volumetric flasks, $12 \mathrm{kDa}$ dialysis tubing (cellulose membrane, Sigma), and commonly various glassware.

\section{Materials}

Pigskin was purchased from the traditional market (Pasar agung, Depok, Indonesia), undenatured collagen-II (Inter Health, Nutraceuticals Incorporated), standard of amino acid glycine, proline, and hydroxyproline (Sigma-Aldrich), FMOC-Cl (Hangzhou Dingyan Chem Co. Ltd), Casson's trichrome staining (Pathology laboratory, PSSP IPB), Reagent pro HPLC, acetonitrile, methanol, $\mathrm{NaOH}$, boric acid, glacial acetic acid, anhydrate acetic sodium, $\mathrm{HCl}$, and $\mathrm{NaCl}$ (Merck), Aqua Pro Injection (Ikapharmindo Putramas), and Aquadest (Brataco) were of reagent grade or higher

\section{Production of collagen standard solution}

About $50 \mathrm{mg}$ of standard collagen was dissolved in $5 \mathrm{~mL}$ of $6 \mathrm{~N} \mathrm{HCl}$ and hydrolyzed in the oven at $110^{\circ} \mathrm{C}$ for $22,23,24$, and $25 \mathrm{~h}$. It was then dissolved in an acetic buffer ( $\mathrm{pH} 4.2$ ) and diluted to a final concentration of $10 \mu \mathrm{g} / \mathrm{mL}$.

\section{Production of the amino acid stock solution}

The glycine amino acid standard, proline, and hydroxyproline were each weighed to as much as $50 \mathrm{mg}$ and then diluted in $100 \mathrm{~mL}$ of 0.1 $\mathrm{M} \mathrm{HCl}$. The solution was further diluted to a final concentration of $10 \mu \mathrm{g} / \mathrm{mL}$ was achieved.

\section{Preparation of the FMOC-Cl solution}

The FMOC-Cl solution (15 mM) was prepared by weighing 39 mg FMOC$\mathrm{Cl}$ (BM $258.7 \mathrm{~g} / \mathrm{mol}$ ) and dissolving it in $10 \mathrm{~mL}$ acetonitrile. The solution was further diluted to a final concentration of $1.5 \mathrm{mM}$ was achieved.

\section{Preparation of boric buffer (pH 9)}

Boric buffer ( $100 \mathrm{mM}$ ) was prepared by weighing $0.0618 \mathrm{~g}$ of boric acid and adding it to $100 \mathrm{~mL}$ of aquabidest. The solution was then diluted to a final concentration of $10 \mu \mathrm{g} / \mathrm{mL}$ was achieved. Next, the $\mathrm{pH}$ was measured until it reached 9 by adding $6 \mathrm{~N} \mathrm{NaOH}$ dropwise.

\section{Preparation of acetic buffer}

Acetic buffer $(15 \mathrm{mM})$ solution was prepared by weighing $1.6 \mathrm{~g}$ of anhydrate acetic sodium and dissolving it in $400 \mathrm{~mL}$ of Aquadest. The $\mathrm{pH}$ level was then adjusted with glacial acetic acid until it reached 4.2. The finished product of acetic buffer was then filtered using Whatman filter paper number 45 .

\section{Experimental steps}

\section{Pre-treatment materials}

Porcine skin was washed in water and manually cleaned from its fat with a knife. It was then cut into $\pm 1 \times 1 \mathrm{~cm}^{2}$ pieces. Next, the pieces were immersed in $0.1 \mathrm{~N} \mathrm{NaOH}$ at a 1:5 ratio for 3 days. The solution was replaced each day.

\section{Collagen extraction from porcine skin}

Sample extraction was performed by immersing porcine skin that had been cut into small pieces in $0.5 \mathrm{M}$ acetic acid for 3 days. The filtrate was then obtained and designated as Filtrate 1 . The porcine skin residue was then immersed in a new $0.5 \mathrm{M}$ acetic acid solution for 3 days, and the filtrate was obtained again (Filtrate 2). Filtrates 1 and 2 were stored in the freezer for 1 day and then mixed and precipitated with $0.9 \mathrm{M} \mathrm{NaCl}$ overnight. The filtrate was then centrifuged at $4000 \mathrm{rpm}$ for $20 \mathrm{~min}$ at $4^{\circ} \mathrm{C}$. The formed sediment was obtained and further dissolved in $0.5 \mathrm{M}$ acetic acid.

\section{Collagen purification}

Purification was performed by dialyzing collagen in a cellophane membrane with $0.1 \mathrm{M}$ acetic acid at a 1:10 ratio from the collagen solution volume for 1 day. The solution was replaced each day for 2 days using Aquadest. Collagen from the dialysis process was then lyophilized (freeze-dried) to obtain its solid form.

\section{Porcine skin collagen characterization}

Organoleptic test

The organoleptic test was conducted by evaluating the appearance, color, and smell of collagen isolated from porcine skin

\section{Functional group analysis with FTIR}

For functional group analysis, $200 \mathrm{mg} \mathrm{KBr}$ and $2 \mathrm{mg}$ collagen were weighed, and the ingredients were mixed and milled until homogenous and then placed on a disk. The disc was placed on the DRS-8000 FTIR device and measured at a $4000-400 \mathrm{~cm}^{-1}$ wavelength to obtain the IR spectrum.

\section{pH determination}

Sample and standard collagen were each weighed at $1 \mathrm{~g}$ and dissolved in $70 \mathrm{~mL}$ of Aquadest. Electrodes of the $\mathrm{pH}$ meter device were immersed into each solution until a stable $\mathrm{pH}$ level was reached.

\section{Casson's trichrome staining}

Isolated collagen was placed on a glass slide and immersed in Casson's trichrome solution for $5 \mathrm{~min}$ and washed with water for 3-5 s, and the water was absorbed with a filter paper until dry. A quick dehydration was then performed in $100 \%$ alcohol, purified in xylol, and closed with a glass coverslip. Observation was performed under a light microscope with a $\times 10$ objective.

\section{Water content test}

A glass weighing bottle was weighed and dried in an oven at $105^{\circ} \mathrm{C}$ for $1 \mathrm{~h}$. The bottle was then placed in a desiccator for $5 \mathrm{~min}$ and weighed again until a fixed weight $(\mathrm{A})$ was achieved. The sample $(1 \mathrm{~g})$ was then added to the bottle and weighed (B). The bottle containing the sample was placed in an oven at $105^{\circ} \mathrm{C}$ for $5-6 \mathrm{~h}$ and then placed in a desiccator and weighed again (C). The water content (\%) was measured using the following formula:

$$
\frac{B-C}{B-A} \times 100
$$

\section{Ash content test}

A goblet was weighed and dried in an oven at $105^{\circ} \mathrm{C}$ for $30 \mathrm{~min}$. The goblet was then taken into the desiccator for $5 \mathrm{~min}$ and reweighed until a fixed weight was achieved. The sample $(1 \mathrm{~g})$ was then added into the goblet and burned on an electric stove until the smoke disappeared. It was then placed in an oven at $600^{\circ} \mathrm{C}$ for $7 \mathrm{~h}$. After that, the goblet and the sample were placed in the desiccator, weighed, and measured for their ash contents.

\section{Viscosity test}

A collagen sample solution was made at $0.5 \%$ concentration in Aquadest and dissolved in hot water. The measurement was performed using an Ostwald viscometer. The test was conducted thrice on the same sample.

\section{Amino acid derivatization}

Amino acid derivatization was performed at room temperature with the pre-column procedure. Briefly, $300 \mu \mathrm{l}$ of the collagen solution was added with $300 \mu \mathrm{l}$ of $10 \mathrm{mM}$ boric buffer (pH 9) and $300 \mu \mathrm{L}$ of $1.5 \mathrm{mM}$ FMOC-Cl. The test solution was then injected (with up to $20 \mu l$ ) into the HPLC device.

\section{Determination of optimum analysis conditions Optimum wavelength determination}

The derivatized standard collagen solution was tested to determine the emission wavelength at 320,325 , and $330 \mathrm{~nm}$. The excitation wavelength was determined using a UV-Vis spectrophotometer for hydroxyproline, glycine, and proline amino acid standard solution. 
The mobile phase composition was tested with acetic buffer (pH 4.2):acetonitrile with ratios of 55:45, 60:40, and 65:35. The mobile phase flow rate (of the selected mobile phase composition) was tested at $0.8,1.0$, and $1.2 \mathrm{~mL} / \mathrm{min}$

\section{System suitability test}

The standard collagen solution that had been derivatized was injected (with up to $20 \mu \mathrm{l}$ ) into the HPLC device with the selected mobile phase composition and flow rate. The parameters of retention time, tailing factor, resolution, column efficiency, and coefficient variation were observed over six injections.

\section{Calibration curve and linearity test}

The calibration curve test solution was prepared from proline, glycine, and hydroxyproline amino acid standard solution mix, with a concentration range of $1,2,4,5,10$, and $20 \mu \mathrm{g} / \mathrm{mL}$. Each solution was injected at $20 \mu \mathrm{l}$ into the HPLC device under the selected analysis conditions. From the obtained results, the peak regression was analyzed (y) toward the analyte concentration (x), and a calibration curve was obtained. The correlation coefficient $(\mathrm{r})$ from the linear regression line equation was then calculated.

\section{Determination of detection limit (LOD) and quantitation limit} (LOQ)

The least detected concentration was measured as the LOD and LOQ detected with statistic measurements obtained from the linear regression calibration curve.

\section{Determination of amino acid content from collagen isolated from porcine skin}

Solid collagen (50 mg) was weighed and dissolved in $5 \mathrm{~mL}$ of $6 \mathrm{~N} \mathrm{HCl}$. The solution was hydrolyzed in an oven at $110^{\circ} \mathrm{C}$ for $22,23,24$, and $25 \mathrm{~h}$. After that, it was dissolved in acetic buffer $(\mathrm{pH} 4.2)$ and diluted to a final concentration of $10 \mu \mathrm{g} / \mathrm{mL}$. The collagen solution was then derivatized with FMOC-Cl and boric buffer and analyzed using the HPLC device at the selected analysis conditions. The size of the obtained peak was recorded, and the test was repeated at least thrice. The concentration was measured using the calibration curve equation.

\section{RESULTS AND DISCUSSION}

\section{Extraction and isolation of collagen from porcine skin}

In this study, the extraction and isolation of collagen from fresh porcine skin of an average weight of $1000 \mathrm{~g}$ were performed in three phases. In the pre-treatment phase, the porcine skin was washed with water, cleaned from its dirt and fat, and cut into small pieces of approximately $1 \times 1 \mathrm{~cm}^{2}$ to achieve a large surface size. The pieces were then immersed in $0.1 \mathrm{~N} \mathrm{NaOH}$ to remove non-collagen protein and minerals and pigment contaminants present in the samples. After immersion in $\mathrm{NaOH}$, porcine skin became white and very clean. Cleansing was initiated by $\mathrm{NaOH}$, which binds to dirt and non-collagen proteins; thus, the porcine skin color became whiter compared with the initial pinkish color before immersion. Furthermore, porcine skin also absorbs $\mathrm{NaOH}$ solution, which led to an increase in its weight [4-7]

The extraction proceeded with the immersion process of porcine skin into $0.5 \mathrm{M}$ acetic acid for 3 days. The combined filtrate was then precipitated with $0.9 \mathrm{M} \mathrm{NaCl}$ overnight. The precipitation process produced a white sediment at the bottom of the solution. Salting out was performed to take out collagen protein that was dissolved in the acetic acid, which represents insoluble protein [4]. Next, the insoluble collagen content was separated with centrifugation at $4000 \mathrm{rpm}$ for $20 \mathrm{~min}$ at $4^{\circ} \mathrm{C}$. Low temperature should be maintained during centrifugation so that collagen proteins do not denature from the spin speed, which may cause the heat to rise. White sediment was formed at the bottom of the centrifugal tube; this sediment was then taken and dissolved in $0.5 \mathrm{M}$ acetic acid.
The purification phase was performed by dialyzing the white collagen sediment from centrifugation through $0.1 \mathrm{M}$ acetic acid and Aquadest in a cellophane membrane of $12 \mathrm{kDa}$. Diffusion is the principal process of dialysis, where the solution and $\mathrm{NaCl}$ in collagen diffuse across the membrane, leaving large-sized collagen molecules stuck in the membrane. The collagen from the dialysis process was then lyophilized (freeze-dried) to obtain its solid or dried form.

\section{Porcine skin collagen characterization}

Organoleptic test

The collagen end product was dried, and the fiber was white and had a fishy smell and a cotton-like appearance (Fig. 1).

\section{Functional group analysis}

FTIR spectrum analysis on the sample and on standard collagen showed peaks of amide A absorption area at $3200-3400 \mathrm{~cm}^{-1}$, amide B at 2935$2915 \mathrm{~cm}^{-1}$, amide I at $1600-1690 \mathrm{~cm}^{-1}$, amide II at $1480-1575 \mathrm{~cm}^{-1}$, and amide III at $1229-1301 \mathrm{~cm}^{-1}$, and each had the typical absorption seen in collagen. Amide A was a stretching vibration of $\mathrm{NH}$, amide $\mathrm{B}$ was an area of asymmetrical $\mathrm{CH}_{2}$, amide I was a vibration group of $\mathrm{C}=0$, amide II was the area of the $\mathrm{NH}$ bond bound with $\mathrm{CN}$, and the amide III was the $\mathrm{CN}$ group with the $\mathrm{NH}$ bond.

\section{pH test}

A $\mathrm{pH}$ test was conducted by comparing the sample with the $\mathrm{pH}$ of standard collagen. The $\mathrm{pH}$ obtained from the standard solution was 6.70, and the $\mathrm{pH}$ of the sample collagen was 6.87. The standard and sample collagen $\mathrm{pH}$ levels in this study were acceptable based on collagen quality conditions standardized by the Badan Standardisasi Nasional (2014), which ranges between 6.5 and 8 [11].

\section{Casson's trichrome staining}

The collagen detection test was conducted with Casson's trichrome solution, which comprised aquadest $(200 \mathrm{~mL})$, phosphotungstic acid $(1 \mathrm{~g})$, orange $\mathrm{G}(2 \mathrm{~g})$, aniline blue $(1 \mathrm{~g})$, and acid fuchsin $(3 \mathrm{~g})$. Collagen staining with Casson's trichrome showed that the isolated porcine

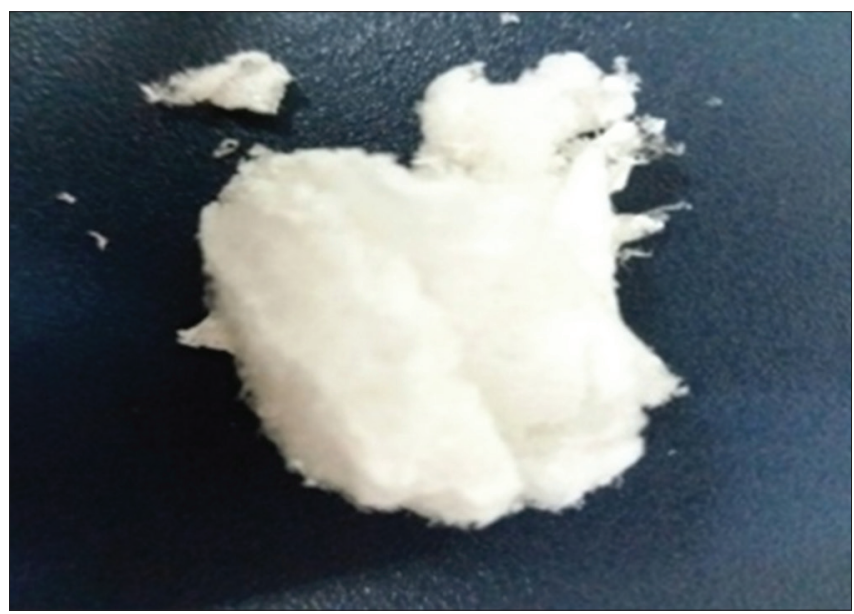

Fig. 1: Freeze-dried collagen

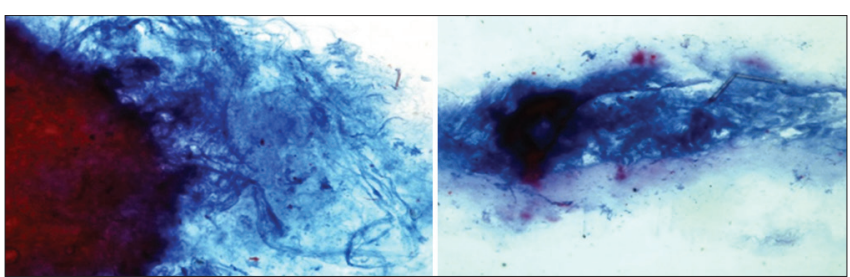

Fig. 2: Staining of porcine collagen with Casson's trichrome 
collagen tissue stained blue and red (Fig. 2). The blue color came from the aniline blue stain showing the existence of collagen, whereas the red color came from the phosphotungstic acid and orange that stained the cytoplasm, muscle, and cell core $[10,12]$.

\section{Water content analysis}

Based on the test results of the isolated porcine skin collagen sample, the obtained water content was $1.186 \%$ on Test I and $1.662 \%$ on Test II. The average obtained number was $1.424 \%$. These results indicated that the water content of the sample fulfilled the BSN conditions (2014) set at $\leq 12$.

\section{Ash content analysis}

Ash content analysis was performed to evaluate whether other minerals, such as silicate, calcium, and potassium, were present in high volume in the sample. If the ash content value is high, then this typically means that the extraction process is not satisfactorily performed. The ash content test on the collagen sample was performed in two cycles, and the obtained values were $0.23 \%$ and $0.49 \%$, respectively. These values fulfilled the criteria of collagen quality based on BSN (2014), which is set at $\leq 1.0$

\section{Viscosity test}

Measurements of viscosity were performed using an Ostwald viscometer at least thrice for the sample solution. Viscosity values were $0.9121 \mathrm{cP}$, $1.1121 \mathrm{cP}$, and $1.022 \mathrm{cP}$. Low viscosity values indicate that the fluids are very dilute (low viscous), which is caused by sample dissolution with hot water, and thus, hydrogen bond degradation occurs in collagen.

\section{Hydrolysis time optimization}

Hydrolysis was performed through the deamination of the amine group of collagen with $6 \mathrm{~N} \mathrm{HCL}$ and heated up to $110^{\circ} \mathrm{C}$ to debond the peptide chain in collagen and form amino acid elements. Hydrolysis times tested were 22, 23, 24, and $25 \mathrm{~h}$. Hydrolysis in the 24-h period yielded the biggest and the most suitable peak width based on Schrieber and Gareis (2007) compared with that with 22-, 23-, and 25-h period. On the chromatogram, the 22-, 23-, and 25-h amino acids were not perfectly separated. Therefore, the most optimum time to hydrolyze the collagen was $24 \mathrm{~h}$ (Table 1$)$.

\section{Formation of the derivate element}

The amino acid derivation process was performed at room temperature using the pre-column procedure and FMOC-Cl. The derivatization that occurred was a substitution reaction where the $\mathrm{Cl}$ group of FMOC-Cl was replaced by a primary and secondary amino acid amine group.

Table 1: Various hydrolysis times in relation to the peak width of the formed derivate element

\begin{tabular}{llll}
\hline \multirow{2}{*}{ Hydrolysis time (h) } & \multicolumn{3}{l}{ Peak width $(\mathbf{m V} / \mathbf{s})$} \\
\cline { 2 - 4 } & Hydroxyproline & Glycine & Proline \\
\hline 22 & 94,073 & 203,781 & 365,141 \\
23 & 57,014 & 156,464 & 201,178 \\
24 & 63,202 & 238,078 & 141,636 \\
25 & 24,087 & 155,995 & 80,549 \\
\hline
\end{tabular}

Derivatization of amino acids with FMOC-Cl requires an alkaline $\mathrm{pH}$ ( $\mathrm{pH} \geq 8$ ). In contrast, the collagen solution test had a $\mathrm{pH}$ level of 6.5-8, which was caused by dissolution with the acetic buffer. In this regard, the addition of buffer was needed to raise the $\mathrm{pH}$ of the test solution. For the derivatization process, boric buffer ( $\mathrm{pH} 9$ ) was used to alkalize the collagen.

A stociometry calculation was first performed to determine the volume needed to produce optimum and stable derivatives. From this study, $300 \mu \mathrm{l}$ of collagen test solution was used, and $300 \mu \mathrm{l}$ of FMOC-Cl and $300 \mu \mathrm{l}$ of boric buffer for the derivating agent were needed.

\section{Determination of wavelength}

The determination of the optimum wavelength was very important when performing analysis with the HPLC fluorescence detector because it could increase the selectivity and sensitivity of the analyzed element. For the excitation wavelength, adjustments with the UV-Vis spectrophotometer and emission wavelength with the fluorescence detector were performed. Wavelength optimization results showed that the best excitation wavelength was $265 \mathrm{~nm}$ and that for emission was $320 \mathrm{~nm}$, which gave the biggest peak width compared to an emission chromatogram of 325 and $330 \mathrm{~nm}$ (Table 2).

\section{Optimum analysis conditions}

The derivatized was very important when analized amino acids from collagen. The derivatized were polarized elements, and thus, a polarized mobile phase was needed. A polarized mobile phase comprising acetic buffer-acetonitrile was used in this study to achieve a good separation with a short retention time.

Using an acetic buffer mobile phase (pH 4.2):acetonitrile (55:45), all three amino acid elements (glycine, proline, and hydroxyproline) appeared, and the best separation occurred compared with the mobile phase chromatograph of $60: 40$ and $65: 35$. This was because the compositions of 60:40 and 65:35 were not polarized enough, and thus, the elements had a low affinity toward the mobile phase, which caused the amino acid components not to separate well.

We also optimized the flow rate by evaluating our results at $0.8,1.0$, and $1.2 \mathrm{~mL} / \mathrm{min}$. Our findings indicated that optimum results were achieved with $0.8 \mathrm{~mL} / \mathrm{min}$, which resulted in the highest resolution (>1.5), good separation, lower HETP values, and more theoretical plates with columnar efficiency.

\section{System suitability test}

The system suitability test was conducted 6 times in a row on standard collagen solution injected under the selected optimum analysis conditions and resulted in coefficiency values for hydroxyproline, glycine, and proline amino acids of $0.88 \%, 0.49 \%$, and $1.40 \%$, respectively. Based on these test results, the experiment fulfilled the conditions of a variation coefficient of no more than $2.0 \%$. In addition, all six injections showed good columnar efficiency values and resolutions of $>1.5$

\section{Calibration curve and linearity test}

Based on linear regression statistic calculation results, the obtained calibration curve line equation was $y=1655.4 x+26980$ for hydroxyproline, $y=9351.2 x+30431$ for glycine, and $y=5824.4 x+38859$

Table 2: Emission wavelength variation data toward the formed derivate element

\begin{tabular}{|c|c|c|c|c|}
\hline \multicolumn{2}{|l|}{ Wavelength } & \multicolumn{3}{|c|}{ Peak width $(\mathrm{mV} / \mathrm{s})$} \\
\hline Excitation (nm) & Emission (nm) & Hydroxyproline & Glycine & Proline \\
\hline 265 & $\begin{array}{l}320 \\
325 \\
330\end{array}$ & $\begin{array}{l}63202 \\
16392 \\
-\end{array}$ & $\begin{array}{l}238078 \\
16196 \\
14817\end{array}$ & $\begin{array}{l}141636 \\
9343 \\
3902\end{array}$ \\
\hline
\end{tabular}


for proline. From the linearity test, the resulting correlation coefficient values (r) for hydroxyproline, glycine, and proline were 0.9981, 0.9979, and 0.9985 .

Our results showed that the correlation coefficient value was not $\geq 0.999$. This was because the calibration curve solution was made by mixing all three amino acids at once, rather than separately. In addition, the derivatization process also had a correlation coefficient of $<0.999$.

\section{Determination of the $L O D$ and $L O Q$}

Based on linearity test results of hydroxyproline, glycine, and proline, the LOD value was $0.900 \mu \mathrm{g} / \mathrm{mL}, 0.990 \mu \mathrm{g} / \mathrm{mL}$, and $0.998 \mu \mathrm{g} / \mathrm{mL}$, respectively. The LOQ for hydroxyproline, glycine, and proline was $3.001 \mu \mathrm{g} / \mathrm{mL}, 3.301 \mu \mathrm{g} / \mathrm{mL}$, and $3.327 \mu \mathrm{g} / \mathrm{mL}$, respectively. Based on these results, the LOQ value was not in the range of the concentrations used in the calibration curve test. However, the LOQ test alone was correlated with the linearity test results.

\section{Determination of the glycine, proline, and hydroxyproline amino acid content}

The amino acid content was determined based on the linear regression equation for each amino acid. Based on the obtained results, the average content of hydroxyproline, glycine, and proline amino acids was $11.303 \pm 0.354 \%, 33.663 \pm 0.215 \%$, and $12.333 \pm 0.128 \%$, respectively. The average contents of hydroxyproline, glycine, and proline amino acids were similar to those based on Schrieber and Gareis (2007), which reported a $33 \%$ glycine content, $11 \%$ proline content, and $10 \%$ hydroxyproline content. The collagen content increase was caused by the porcine skin samples, which have a higher protein content.

\section{CONCLUSION}

Extracted and isolated collagen from porcine skin was obtained, with a yield value of $0.974 \%$ (bb) confirmed by functional group analysis with FTIR and Casson's trichrome staining. Optimum analysis conditions to determine the hydroxyproline, glycine, and proline amino acid content of isolated collagen from porcine skin withHPLC and fluorescence detector were observed with $\lambda_{\mathrm{ex}}=265 \mathrm{~nm}$ and $\lambda_{\mathrm{em}}=320 \mathrm{~nm}$, YMC-Triart ${ }^{\circledR}$ C18 column (column length, $250 \mathrm{~nm}$; diameter size, $4.6 \mathrm{~mm}$; and particle size, $5 \mu \mathrm{m}$ ), and a mobile phase of acetic buffer ( $\mathrm{pH} 4.2$ ):acetonitrile (55:45), with a flow rate of $0.8 \mathrm{~mL} / \mathrm{min}$. Optimum conditions for collagen hydrolysis were observed with $6 \mathrm{~N} \mathrm{HCl}$, followed by heating at $110^{\circ} \mathrm{C}$ for $24 \mathrm{~h}$. The collagen solution was then added with boric buffer $(\mathrm{pH} 9)$ and derivatized with FMOC-Cl at as much as $300 \mu \mathrm{l}$ and then injected into the HPLC device with an injection volume of $20 \mu \mathrm{l}$.
Based on our analysis results, the amino acid content of collagen isolated from porcine skin for hydroxyproline, glycine, and proline averaged $11.303 \pm 0.354 \%, 33.663 \pm 0.215 \%$, and $12.333 \pm 0.128 \%$, respectively.

\section{ACKNOWLEDGMENTS}

All authors acknowledge Universitas Indonesia for support and PITTA Research Grants 2017.

\section{CONFLICTS OF INTEREST}

Authors declare no conflicts of interest in this research.

\section{REFERENCES}

1. Meyer M, Schröpfer M. Collagen Materials - Collagen Processing. Istanbul, Turkey: Technical Freedom and Scientific Challenges when Transforming Collagen into Final Materials; 2013.

2. Yang H, Shu Z. The extraction of collagen protein from pig skin. J Chem Pharm Res 2014;6:683-7.

3. Gomez-Guillen MC, Gimenez B, Lopez-Caballero ME, Montero MP. Functional and bioactive properties of collagen and gelatin from alternative sources: A review. Food Hydrocolloids 2011;25:1813-27.

4. Liu SH, Yang RS, al-Shaikh R, Lane JM. Collagen in tendon, ligament, and bone healing. A current review. Clin Orthop Relat Res 1995;318:265-78.

5. Nithya V, Brinda P, Anand KV. Wound healing activity of Leonotis nepetaefolia R.br, in wistar albino rats. Asian J Pharm Clin Res 2011;4:23-6.

6. Hossain CM, Maji HS, Chakrabority P. Hepatoprotective activity of Lawsonia inermis linn, warm aqueous extract in carbon tetrachlorideinduced hepatic injury in wister rats. Asian $\mathrm{J}$ Pharm Clin Res 2011;4:106-9.

7. Surya GV, Vishal GN, Gowda DV. Research and development in wound management products: A brief review. Asian J Pharm Clin Res 2018;11:17-24

8. Nagai T, Suzuki N. Isolation of collagen from fish waste material - Skin, bone and fins. Food Chem 2000;68:277-81.

9. Lestari T. Isolation and Collagen Characterization from Thumnus Albacares as Raw Material Pharmacy Industry. Thesis. Depok: Faculty of Mathematics and Natural Sciences, Universitas Indonesia; 2007. p. 83 .

10. Rahadini IR. Isolation and Collagen Characterization of Cyprinus carplo as Pharmaceutical Industry Raw Materials. Thesis. Depok: Faculty of Pharmacy, Universitas Indonesia; 2007.

11. National Standardization Agency. Crude collagen from fish scales- Quality and preparation requirement: SNI 8076-2014; 2014

12. Kiernan JA. Histological and Histochemical Methods: Theory and Practice. Great Britain: Pergamon PR; 1990. 